\title{
PD-L1 expression in inflammatory myofibroblastic tumors
}

\author{
Tricia R Cottrell 1,2 Anh T Duong ${ }^{2,3} \cdot$ Christopher D Gocke $\mathbb{D}^{1} \cdot$ Haiying $\mathrm{Xu}^{4} \cdot$ Aleksandra Ogurtsova $^{4}$. \\ Janis M Taube ${ }^{2,4} \cdot$ Deborah A Belchis $^{1}$
}

Received: 24 July 2017 / Revised: 29 December 2017 / Accepted: 30 December 2017

(c) United States \& Canadian Academy of Pathology 2018

\begin{abstract}
Inflammatory myofibroblastic tumor is a rare mesenchymal tumor occurring at many anatomic sites, with a predilection for children and young adults. Often indolent, they can be locally aggressive and can metastasize, resulting in significant morbidity and mortality. Therapeutic options are often limited. The identification of underlying kinase mutations has allowed the use of targeted therapy in a subset of patients. Unfortunately, not all tumors harbor mutations and resistance to tyrosine kinase inhibitor therapy is a potential problem. We hypothesized that these tumors may be amenable to PD-L1 therapy given the immune nature of the tumor. PD-L1 expression in inflammatory myofibroblastic tumors has not yet been defined. The purpose of this study was to explore PD-L1 expression in inflammatory myofibroblastic tumors, as adaptive PD-L1 expression is known to enrich for response to anti-PD-1/PD-L1 therapies. Expression of PD-L1 (clone SP142) was assessed in 35 specimens from 28 patients. Positivity was defined as membranous expression in $\geq 5 \%$ of cells and evaluated separately in tumor and immune cells. Adaptive vs. constitutive patterns of tumor cell PD-L1 expression were assessed. PD-L1 status was correlated with clinicopathologic features. $\mathrm{CD} 8^{+} \mathrm{T}$ cell infiltrates were quantified by digital image analysis. ALK status was assessed by immunohistochemistry and/or FISH. Twenty-four (69\%) tumors had PD-L1(+) tumor cells and $28(80 \%)$ showed PD-L1(+) immune cells. Most recurrent and metastatic tumors $(80 \%)$ and ALK $(-)$ tumors $(88 \%)$ were PD-L1(+). Adaptive PD-L1 expression was present in 23 (96\%) of PD-L1(+) tumors, which also showed a three-four fold increase in $\mathrm{CD}^{+} \mathrm{T}$ cell infiltration relative to PD-L1(-) tumors. Constitutive PD-L1 expression was associated with larger tumor size $(p=0.002)$. Inflammatory myofibroblastic tumors show frequent constitutive and adaptive PD-L1 expression, the latter of which is thought to be predictive of response to anti-PD-1. These data support further investigation into PD-1/PD-L1 blockade in this tumor type.
\end{abstract}

Inflammatory myofibroblastic tumors are rare mesenchymal tumors, which can arise at any age and throughout the body. While often indolent in their behavior a subset of tumors are

These authors contributed equally: Janis M Taube, Deborah A Belchis.

$\triangle$ Deborah A Belchis

dbelchi1@jhmi.edu

1 Department of Pathology, The Johns Hopkins University School of Medicine, Baltimore, MD, USA

2 The Bloomberg Kimmel Institute for Cancer Immunotherapy, The Sidney Kimmel Comprehensive Cancer Center, The Johns Hopkins University School of Medicine, Baltimore, MD, USA

3 Department of Oncology, The Johns Hopkins University School of Medicine, Baltimore, MD, USA

4 Department of Dermatology, The Johns Hopkins University School of Medicine, Baltimore, MD, USA locally aggressive and metastases have been reported in up to $5 \%$ of cases $[1,2]$. Up until recently, surgery was the treatment of choice with its associated morbidity. The recent identification of underlying kinase mutations in many, if not all, of these tumors has allowed for the use of targeted therapy. The most common mutation identified is rearrangement in anaplastic lymphoma kinase $(A L K)$ [3] present in $\sim 50-70 \%$ of cases. A smaller subset of inflammatory myofibroblastic tumors have been associated with alternate gene fusions, including ROS1 (5-10\%), NTRK3, RET, and $P D G F R B$ [3-6]. Good response to tyrosine kinase inhibitors has been reported. However, as has been seen in other tumors treated with tyrosine kinase inhibitor therapy, the development of acquired resistance in inflammatory myofibroblastic tumors $[3,7]$ has also been noted. In addition, not all inflammatory myofibroblastic tumors harbor actionable mutations. Thus, novel treatment options are highly desirable. The immunologic nature of inflammatory myofibroblastic tumors demonstrated by the prominent 
tumor-associated inflammatory infiltrate and the constitutional symptoms, including fever, anemia, and weight loss, which can afflict some patients suggests an immunologicbased therapeutic approach, specifically PD-1/PD-L1 blockade, may be worth exploring. PD-L1 expression in inflammatory myofibroblastic tumors has not yet been defined. The purpose of this study was to explore PD-L1 expression in inflammatory myofibroblastic tumors, as PDL1 is known to enrich for response to anti-PD-1/PD-L1 therapies in many other tumor types [8, 9].

\section{Materials and methods}

\section{Clinical data}

The study was approved by the Johns Hopkins Medicine institutional review board. Thirty-five inflammatory myofibroblastic tumor specimens obtained from 28 patients between 1998 and 2015 were retrieved from the surgical pathology archives. A surgical pathologist (DAB) reviewed the hematoxylin and eosin (H\&E)-stained slides to confirm the diagnosis. Clinicopathologic information was obtained from the medical records (Tables 1 and 2). Tumor size was based on gross specimen examination if completely excised and intact or radiographic assessment at the time of tissue sampling. For patients with multiple tumor foci, only the size corresponding to the sampled tumor was assessed. For patients with multiple specimens, only those obtained from different time points or locations were studied. ALK status was assessed by immunohistochemistry and/or FISH. One activating ROS1 fusion (TGF-ROS1) was identified by genomic sequencing. The remaining ALK-negative specimens were assessed for ROS1 translocation by FISH. Fusion-positive inflammatory myofibroblastic tumors, defined as those with $A L K$ or ROS1 genetic rearrangements, were assessed as a group.

\section{Assessment of histopathologic features}

The histologic subtypes were classified as: (1) fascicular or leiomyomatous-like, (2) fasciitis-like, (3) desmoid-like, and (4) epithelioid [1]. Tumor cellularity, tumor cell morphology and pleomorphism, mitotic rate, and necrosis were also scored. The composition (lymphocytes, plasma cells, eosinophils, and/or neutrophils) of the inflammatory cell infiltrate and the presence of lymphoid aggregates (defined as at least 100 lymphocytes with no germinal center) were assessed on $\mathrm{H} \& \mathrm{E}$.

\section{Immunohistochemical staining and scoring}

Immunohistochemistry for PD-L1 (clone SP142) was performed using a laboratory-derived manual assay as previously described [10]. The percentage of tumor and intratumoral immune cells demonstrating membranous (cell surface) PD-L1 staining were scored separately as $\sim 0 \%$, $5 \%, 10 \%$, and then at increasing $10 \%$ intervals. Cases were scored independently by two board-certified pathologists (JMT and DAB), and cases with $>10 \%$ discordance were adjudicated by consensus. A threshold of $\geq 5 \%$ was used independently for both tumor and immune cells when a case was designated as PD-L1(+). The geographic association of PD-L1 expression with tumor infiltrating lymphocytes was assessed. Patterns of PD-L1 expression were classified as constitutive (PD-L1 expression in absence of tumor infiltrating lymphocytes), adaptive (PD-L1 geographically associated with tumor infiltrating lymphocytes), or adaptive and constitutive (broad PD-L1 expression independent of tumor infiltrating lymphocytes, further accentuated in areas of lymphocyte infiltration).

Immunohistochemistry for CD8 (clone c8/c8144B) was performed using standard automated methods. CD8immunostained slides were scanned using the NanoZoomer-XR (Hamamatsu, Hamamatsu City, Japan). Halo Image Analysis Software (Indica Labs, Corrales, NM) was used to annotate tumor and exclude necrotic, folded, and fragmented areas. Intratumoral $\mathrm{CD}^{+}$cell densities were quantified with the Halo Immune Cell Module using best-fit parameters [10].

\section{Statistical analysis}

The relationships between clinicopathologic features and PD-L1 status were assessed using Fisher's exact test for categorical variables. Correlations between two continuous variables were assessed by Spearman's correlation coefficient. All tests were two-sided and statistical significance was determined with an alpha level of 0.05 .

\section{Results}

\section{Clinicopathologic characteristics}

The clinicopathologic features of each individual case are presented in Table 1. Patients ranged in age from $<1$ month to 77 years, and $10(36 \%)$ were under 20 years old. The most common sites of origin were the lung and abdomen. Tumor specimens included $32(91 \%)$ resections and $3(9 \%)$ biopsies from $26(74 \%)$ primary tumors, 2 (6\%) recurrences, and $7(20 \%)$ metastases. Multiple specimens were available from three patients. Two patients had therapy prior to tissue sampling (Table 1), including one patient who received neoadjuvant radiation therapy and one patient who was treated with chemotherapy for another malignancy. The lack of paired pretreatment and post-treatment specimens preclude analysis regarding whether prior treatment 
Table 1 Summary of clinical characteristics and PD-L1 status for the study cohort

\begin{tabular}{|c|c|c|c|c|c|c|c|c|}
\hline$\overline{\text { Patient }}$ & Tumor & $\begin{array}{l}\text { Age } \\
\text { (years) }\end{array}$ & Description $^{\mathrm{a}}$ & Location & $\begin{array}{l}\text { Size } \\
(\mathrm{cm})\end{array}$ & Alk & $\begin{array}{l}\text { Tumor }{ }^{\mathrm{d}} \text { PD- } \\
\text { L1 }\end{array}$ & $\overline{\text { IC PDL1 }}$ \\
\hline 1 & $\mathrm{~T} 1$ & 0.06 & Primary & Heart & 2.5 & $\mathrm{Neg}$ & Mixed & Pos \\
\hline 2 & $\mathrm{~T} 2$ & 0.42 & Primary & Mediastinum & 4.0 & Pos & Adaptive & Pos \\
\hline 3 & $\mathrm{~T} 3$ & 1.08 & Primary & Extremity & 5.5 & Pos & Adaptive & Pos \\
\hline 4 & $\mathrm{~T} 4$ & 2 & Primary & Mesenteric mass & 9.5 & Pos & Neg & $\mathrm{Neg}$ \\
\hline \multirow[t]{3}{*}{5} & $\mathrm{~T} 5$ & 2.3 & Primary & Liver & 12.5 & Pos & Mixed & Pos \\
\hline & T6 & 2.7 & Metastasis & Omentum & 4.5 & Pos & Mixed & Pos \\
\hline & $\mathrm{T} 7$ & 2.7 & Metastasis & Bowel serosa & 1.7 & Pos & Adaptive & Pos \\
\hline 6 & $\mathrm{~T} 8$ & 4 & Primary & Trachea & 1.7 & Pos & Neg & Pos \\
\hline \multirow[t]{2}{*}{7} & T9 & 9 & Primary & Abdomen & 20 & Pos & Mixed & Pos \\
\hline & $\mathrm{T} 10$ & 9 & Recurrence & Abdomen & 6.5 & Pos & Mixed & Pos \\
\hline 8 & $\mathrm{~T} 11$ & 9 & Primary & Lung & 1.3 & Pos & $\mathrm{Neg}$ & Pos \\
\hline 9 & $\mathrm{~T} 12$ & 10 & Primary & Extremity & 3 & $\mathrm{Neg}^{\mathrm{b}}$ & Adaptive & Pos \\
\hline 10 & $\mathrm{~T} 13$ & 12 & Primary & Brain & 1.9 & $\mathrm{Neg}^{\mathrm{c}}$ & Adaptive & $\mathrm{Neg}$ \\
\hline 11 & $\mathrm{~T} 14$ & 26 & Primary & Pulmonary artery & 5 & Neg & Mixed & Pos \\
\hline 12 & $\mathrm{~T} 15$ & 27 & Primary & Lung & 1.2 & Pos & Neg & Pos \\
\hline 13 & $\mathrm{~T} 16$ & 28 & Primary & Placenta & 3.2 & Pos & Neg & Pos \\
\hline 14 & $\mathrm{~T} 17$ & 30 & Primary & Pelvic mass & 10 & $\mathrm{Neg}^{\mathrm{b}}$ & $\mathrm{Neg}$ & Pos \\
\hline 15 & $\mathrm{~T} 18$ & 35 & Metastasis (lung) & Rectus sheath & 9 & Pos & Neg & Neg \\
\hline 16 & $\mathrm{~T} 19$ & 36 & Metastasis (lung) & Brain & 3.1 & Pos & $\mathrm{Neg}$ & $\mathrm{Neg}$ \\
\hline 17 & $\mathrm{~T} 20$ & 36 & Primary & Lung & 4.5 & Pos & $\mathrm{Neg}$ & $\mathrm{Neg}$ \\
\hline 18 & $\mathrm{~T} 21$ & 37 & Primary & Bladder & 4 & Pos & Mixed & Pos \\
\hline 19 & $\mathrm{~T} 22$ & 39 & Primary & Bladder & 3.6 & Pos & Mixed & Pos \\
\hline 20 & $\mathrm{~T} 23$ & 42 & Primary & Lung & 1 & Pos & Neg & Pos \\
\hline 21 & $\mathrm{~T} 24$ & 43 & Primary & Bladder & 2.2 & Pos & Mixed & Pos \\
\hline 22 & $\mathrm{~T} 25$ & 44 & Primary & Lung & 1.5 & Pos & Adaptive & Pos \\
\hline 23 & $\mathrm{~T} 26$ & 55 & Primary & Liver & 17.5 & $\mathrm{Neg}^{\mathrm{b}}$ & Mixed & Pos \\
\hline 24 & $\mathrm{~T} 27$ & 57 & Primary & Lung & 0.7 & $\mathrm{Neg}^{\mathrm{b}}$ & Adaptive & Pos \\
\hline 25 & $\mathrm{~T} 28$ & 61 & Recurrence ${ }^{\mathrm{e}}$ & Pelvic mass & 6.8 & $\mathrm{Neg}$ & Mixed & Pos \\
\hline \multirow[t]{5}{*}{26} & $\mathrm{~T} 29$ & 61 & Primary ${ }^{\mathrm{f}}$ & Lung & NA & Pos & Adaptive & Pos \\
\hline & T30 & 61 & Primary ${ }^{\mathrm{f}}$ & Lung & 9.5 & Pos & Mixed & Pos \\
\hline & T31 & 65 & Metastasis $^{\mathrm{f}}$ & Chest wall & 7 & Pos & Mixed & Pos \\
\hline & $\mathrm{T} 32$ & 66 & Metastasis $^{\mathrm{f}}$ & Kidney & 9 & Pos & Const. & $\mathrm{Neg}$ \\
\hline & $\mathrm{T} 33$ & 67 & Metastasis $^{\mathrm{f}}$ & Chest wall & 1.5 & Pos & Adaptive & Pos \\
\hline 27 & $\mathrm{~T} 34$ & 74 & Primary & Epiglottis & 0.5 & Pos & Neg & $\mathrm{Neg}$ \\
\hline 28 & T35 & 77 & Primary & Bladder & 2 & Pos & Adaptive & Pos \\
\hline
\end{tabular}

IC immune cell, Pos positive, Neg negative

${ }^{\mathrm{a}}$ When only the metastasis is present, the primary location is noted in parentheses

${ }^{\mathrm{b}} \mathrm{ROS} 1$ rearrangement negative

${ }^{c}$ ROS1 rearrangement positive

${ }^{\mathrm{d}}$ For specimens positive for tumor cell PD-L1 expression, the pattern is noted as adaptive, constitutive (Const.), or mixed

${ }^{\mathrm{e}}$ Prior radiation

${ }^{\text {fPrior }}$ chemotherapy for another malignancy 
Table 2 Clinical characteristics by IMT PD-L1 status

\begin{tabular}{|c|c|c|c|}
\hline Characteristics & $\begin{array}{l}\text { PD-L1 positive } \\
n(\%)\end{array}$ & $\begin{array}{l}\text { PD-L1 negative } \\
n(\%)\end{array}$ & $p$ value $^{\mathrm{a}}$ \\
\hline All patients & 17 & 11 & \\
\hline \multicolumn{4}{|l|}{ Age at resection } \\
\hline$<20$ years & $7(41)$ & $3(27)$ & 0.69 \\
\hline$\geq 20$ years & $10(59)$ & $8(73)$ & \\
\hline Median (years) & 37 & 30 & $0.72^{\mathrm{b}}$ \\
\hline Range (years) & $0.06-77$ & $2-74$ & \\
\hline \multicolumn{4}{|l|}{$\operatorname{Sex}^{\mathrm{c}}$} \\
\hline Female & $10(59)$ & $6(55)$ & 1 \\
\hline Male & $7(41)$ & $5(46)$ & \\
\hline \multicolumn{4}{|l|}{ Race } \\
\hline Caucasian & $11(65)$ & $8(73)$ & 0.69 \\
\hline African American & $4(24)$ & $3(27)$ & \\
\hline Other & $2(12)$ & $0(0)$ & \\
\hline Other malignancy ${ }^{\mathrm{d}}$ & $2(15)$ & $0(0)$ & 0.49 \\
\hline Multifocal disease $^{\mathrm{d}}$ & $3(23)$ & $2(25)$ & 1 \\
\hline \multicolumn{4}{|l|}{ Clinical outcome } \\
\hline $\begin{array}{l}\text { No evidence of } \\
\text { disease }\end{array}$ & $11(65)$ & $6(55)$ & 0.70 \\
\hline Alive with disease & $4(24)$ & $2(18)$ & 1 \\
\hline Died of disease & $1(6)$ & $2(18)$ & 0.54 \\
\hline Lost to follow up & $1(6)$ & $1(9)$ & 1 \\
\hline
\end{tabular}

${ }^{a}$ Fisher's exact test unless otherwise noted

${ }^{\mathrm{b}}$ Wilcoxon rank-sum test

${ }^{c}$ Percentages may not add up to 100 due to rounding

${ }^{\mathrm{d}}$ Data not available for all patients

potentially altered the tumor microenvironment. The median follow-up time was 3.8 years. Nine patients had persistent disease following treatment, including six living with disease and three who died of metastatic disease. Twenty (71\%) of patients' tumors were ALK $(+)$. Among all ALK (-) tumors, one was positive for ROS1 rearrangement, four were negative, and three could not be assessed due to technical failure.

\section{PD-L1 expression on tumor and immune cells in inflammatory myofibroblastic tumor}

Membranous PD-L1 expression was observed on both tumor and immune cells (Fig. 1). Of the 35 specimens analyzed, $24(69 \%)$ had PD-L1 $(+)$ tumor cells and 28 $(80 \%)$ showed PD-L1(+) immune cells. Concurrent tumor and immune PD-L1 expression was observed in $22(63 \%)$ specimens and there was a positive correlation between the proportion of tumor and immune cells expressing PD-L1 $(r=0.48, p=0.0035)$, supporting a component of adaptive PD-L1 expression. Tumor size was positively correlated with the proportion of PD-L1
$(+)$ tumor cells $(r=0.38, p=0.029)$, but not PD-L1 $(+)$ immune cells $(p=0.7)$. The remaining clinicopathologic features assessed did not correlate with tumor cell (Tables 2 and 3) or immune cell (data not shown) PD-L1 expression. Multiple specimens were available from three patients and were concordant for PD-L1 staining (Table 1 and Fig. 2).

\section{PD-L1 expression and the tumor immune microenvironment}

We next sought to determine the association between PDL1 expression and infiltrating immune cells in inflammatory myofibroblastic tumors. Tumors with brisk lymphocytic infiltrates were more likely to express PD-L1 on tumor and immune cells, although the trend was not significant for tumor cell PD-L1 ( $p=0.13$ and $p=0.03$, respectively) (Table 4). PD-L1 expression was not associated with lymphoid aggregates or non-lymphocytic immune infiltrates. Quantification of tumor infiltrating $\mathrm{CD}^{+} \mathrm{T}$ cells by digital image analysis showed a nearly threefold increase in cases with PD-L1 $(+)$ tumor cells $(p=0.085)$ and a fourfold increase in cases with PD-L1 $(+)$ immune cells $(p=0.008)$ (Table 4$)$. The $\mathrm{CD}^{+} \mathrm{T}$ cell density positively correlated with the proportion of PD-L1( + ) immune cells $(r=0.36, p$ $=0.03)$, but not the proportion of PD-L1 $(+)$ tumor cells $(p$ $=0.4$ ). There was no correlation between $\mathrm{CD}^{+} \mathrm{T}$ cell density and tumor size.

Three patterns of tumor cell PD-L1 expression were observed (Fig. 1). Ten (42\%) cases showed an adaptive (tumor infiltrating lymphocyte-associated) expression pattern only, and $1(4 \%)$ case showed a purely constitutive (non-tumor infiltrating lymphocytes-associated) expression pattern. The majority of cases $(n=13,54 \%)$ showed evidence of both adaptive and constitutive PD-L1 expression (Fig. 3). In total, 23 (96\%) of PD-L1(+) tumors showed a component of an adaptive expression pattern.

The pathologist-assessed patterns of PD-L1 expression were supported by $\mathrm{CD}^{+} \mathrm{T}$ cell quantification. Tumors with adaptive tumor cell PD-L1 expression (adaptive only and adaptive + constitutive) showed a threefold increase in CD8 density over those without (379 vs. 126 cells $/ \mathrm{mm}^{2}, p=$ 0.03). When tumors with adaptive tumor cell PD-L1 are combined with those showing immune cell PD-L1 expression, a 4.5-fold increase in CD8 density is observed (377 vs. 83 cells $\left./ \mathrm{mm}^{2}, p=0.005\right)$. In contrast, constitutive tumor cell PD-L1 expression is not associated with CD8 density ( 230 vs. 365 cells $/ \mathrm{mm}^{2}, p=1.0$ ). Inflammatory myofibroblastic tumors with a component of constitutive PD-L1 expression were significantly larger than those without (6.7 $\mathrm{cm}$ vs. $2 \mathrm{~cm}, p=0.002$ ), while there was no association between tumor size and adaptive PD-L1 expression $(p=0.5)$. 
Fig. 1 PD-L1 expression patterns in inflammatory myofibroblastic tumors. H\&E, PD-L1, and CD8

immunohistochemistry stains are shown. Patterns of PD-L1 expression observed include: (row 1) immune cell expression only; (row 2) constitutive (nontumor infiltrating lymphocyteassociated) tumor cell expression; (row 3) adaptive (tumor infiltrating lymphocyteassociated) tumor expression ( \pm immune cell PD-L1). Row 4 shows a combination of adaptive and constitutive expression. Note low-level PDL1 expression in the absence of tumor infiltrating lymphocytes (bottom) that is further enhanced in association with tumor infiltrating lymphocytes (top). Rows $1-3$ are at a magnification of $\times 200$, row 4 is at $\times 100$. Figure 3 shows additional images of combined adaptive and constitutive PD-L1 expression

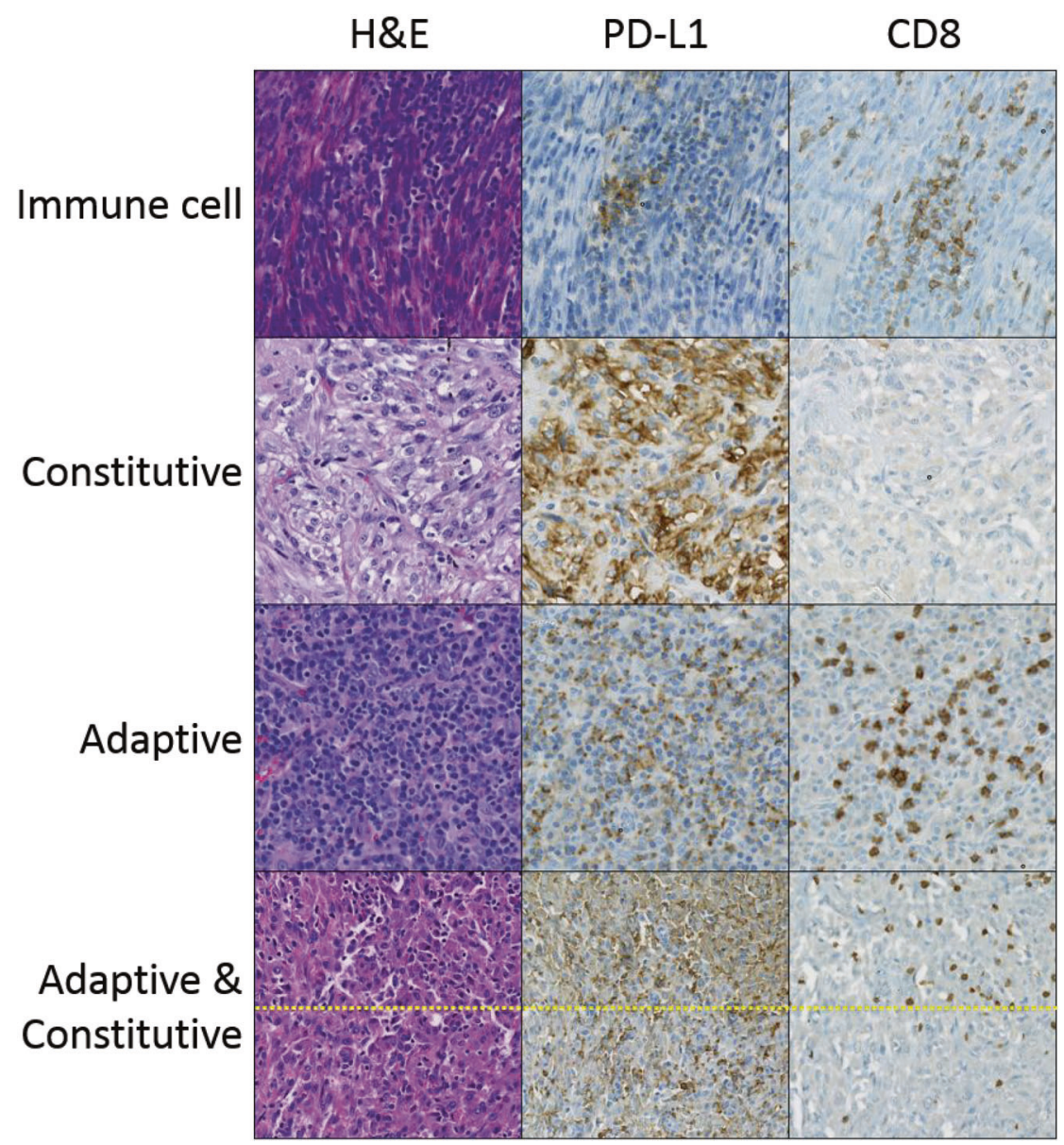

\section{PD-L1 expression and inflammatory myofibroblastic tumor fusion status}

Genetic fusion status, defined as ALK overexpression or ROS1-rearrangment, did not associate with PD-L1 status or PD-L1 expression pattern. However, fusion-negative inflammatory myofibroblastic tumors were enriched for PD-L1(+) immune cells (median of $20 \%$ in fusion-negative vs. $10 \%$ in fusion-positive tumors, $p=0.005$ ). In contrast, the median percentage of PD-L1(+) tumor cells and median $\mathrm{CD}^{+} \mathrm{T}$ cell density were not significantly different in fusion-positive vs. fusion-negative inflammatory myofibroblastic tumors (50 vs. $25 \%$ and 468 vs. 218 cells $/ \mathrm{mm}^{2}, p$ $=0.11$ and $p=0.13$, respectively).

\section{Discussion}

Our findings demonstrate a high prevalence of PD-L1 expression on both tumor and infiltrating immune cells in inflammatory myofibroblastic tumors. Among recurrent and metastatic inflammatory myofibroblastic tumors evaluated, $80 \%$ were PD-L1(+). PD-L1 expression was also prevalent in $\mathrm{ALK}(-)$ inflammatory myofibroblastic tumors (88\%). Although increasing tumor size was associated with constitutive PD-L1 expression, 96\% of PD-L1(+) tumors showed a component of adaptive PD-L1 expression. This latter point is noteworthy, as this pattern of PD-L1 expression is thought to be predictive of response to antiPD-1 [11]. Collectively, these data support further investigation into PD-1/PD-L1 blockade in this tumor type.

Conflicting reports exist about the potential relationship between ALK overexpression in other tumor types and increased constitutive PD-L1 expression [12-15]. In the present study, we found no difference in constitutive (or adaptive) tumor cell PD-L1 expression in ALK(+) vs. ALK $(-)$ inflammatory myofibroblastic tumors. However, among tumors with PD-L1(+) immune cells, ALK $(-)$ tumors were noted to have a significant increase in the proportion of PDL1(+) immune cells. Consequently, PD-1/PD-L1 blockade may be of particular benefit in this subset.

Approximately one-third of patients diagnosed with inflammatory myofibroblastic tumor develop a paraneoplastic syndrome characterized by fever, leukocytosis, and hematologic abnormalities [16]. This syndrome has been ascribed to elevated levels of interleukin 6, a pro- 
Table 3 Histopathologic characteristics by IMT PD-L1 status

\begin{tabular}{|c|c|c|c|}
\hline Characteristic & $\begin{array}{l}\text { PD-L1+ }(n= \\
24)\end{array}$ & $\begin{array}{l}\text { PD-L1- }(n= \\
11)\end{array}$ & $p$ value $^{\mathrm{a}}$ \\
\hline \multicolumn{4}{|l|}{ Tumor size $(\mathrm{cm})$} \\
\hline Median & 4.0 & 3.1 & $0.25^{\mathrm{b}}$ \\
\hline Range & $0.7-20$ & $0.5-10$ & \\
\hline \multicolumn{4}{|l|}{ Location, $n(\%)$} \\
\hline Lung & $4(17)$ & $4(36)$ & 0.23 \\
\hline Abdomen & $6(25)$ & $2(18)$ & 1 \\
\hline Bladder & $4(17)$ & $0(0)$ & 0.28 \\
\hline Extremity/Soft tissue & $2(8)$ & $0(0)$ & 1 \\
\hline Other & $8(33)$ & $5(45)$ & 0.71 \\
\hline \multicolumn{4}{|l|}{ Specimen type, $n(\%)$} \\
\hline Primary & $17(71)$ & $9(82)$ & 0.69 \\
\hline Recurrence & $2(8)$ & $0(0)$ & 1 \\
\hline Metastasis & $5(21)$ & $2(18)$ & 1 \\
\hline \multicolumn{4}{|l|}{ Histologic subtype, $n(\%)$} \\
\hline Fasciitis-like & $18(75)$ & $7(64)$ & 0.69 \\
\hline Fascicular & $6(25)$ & $3(27)$ & 1 \\
\hline Epithelioid & $0(0)$ & $1(9)$ & 0.31 \\
\hline Hypercellularity & $21(88)$ & $10(91)$ & 1 \\
\hline Spindled tumor cells & $24(100)$ & $10(91)$ & 0.31 \\
\hline Cellular pleomorphism & $13(54)$ & $4(36)$ & 0.47 \\
\hline Mitoses (>2/10HPF) & $5(21)$ & $2(18)$ & 1 \\
\hline Necrosis & $8(33)$ & $3(27)$ & 1 \\
\hline
\end{tabular}

${ }^{a}$ Fisher's exact test unless otherwise noted

${ }^{\mathrm{b}}$ Wilcoxon rank-sum test inflammatory cytokine secreted by $\mathrm{T}$ cells and macrophages to stimulate immune response. Here, we found that tumor or immune cell PD-L1 was associated with a 3-4-fold increase in infiltrating $\mathrm{CD}^{+} \mathrm{T}$ cells, which is consistent with the finding that $\mathrm{T}$ cell secretion of interferon gamma can stimulate PD-L1 expression [17]. Notably, several cases of inflammatory myofibroblastic tumor spontaneous regression have been reported [18]. Collectively, these data support the hypothesis that at least a subset of infiltrating lymphocytes may possess the capacity for anti-tumor activity in inflammatory myofibroblastic tumors. Most patients with inflammatory myofibroblastic tumor are cured by complete surgical excision. However, a subset of inflammatory myofibroblastic tumors recur and, in rare instances, progress to metastatic disease. In particular, tumors with RANBP2$A L K$ fusions and epithelioid morphology have been associated with more aggressive behavior [19, 20]. Studies in other soft tissue sarcomas have showed that prevalence of PD-L1 expression varies between histologic subtypes and may be an unfavorable prognostic feature, although reports conflict regarding the latter point, depending on assay used and scoring system [21-25]. Two phase 2 clinical trials of Pembrolizumab (anti-PD-1) in advanced soft tissue sarcomas have reported objective response rates up to $18 \%$ with the few patients with PD-L1-positive tumors among the responders [26, 27].

This study has several limitations. Inflammatory myofibroblastic tumors are rare and only 28 patients had tissue available for study. This cohort was skewed toward adult patients $(64 \%)$, so these results may not be generalizable in

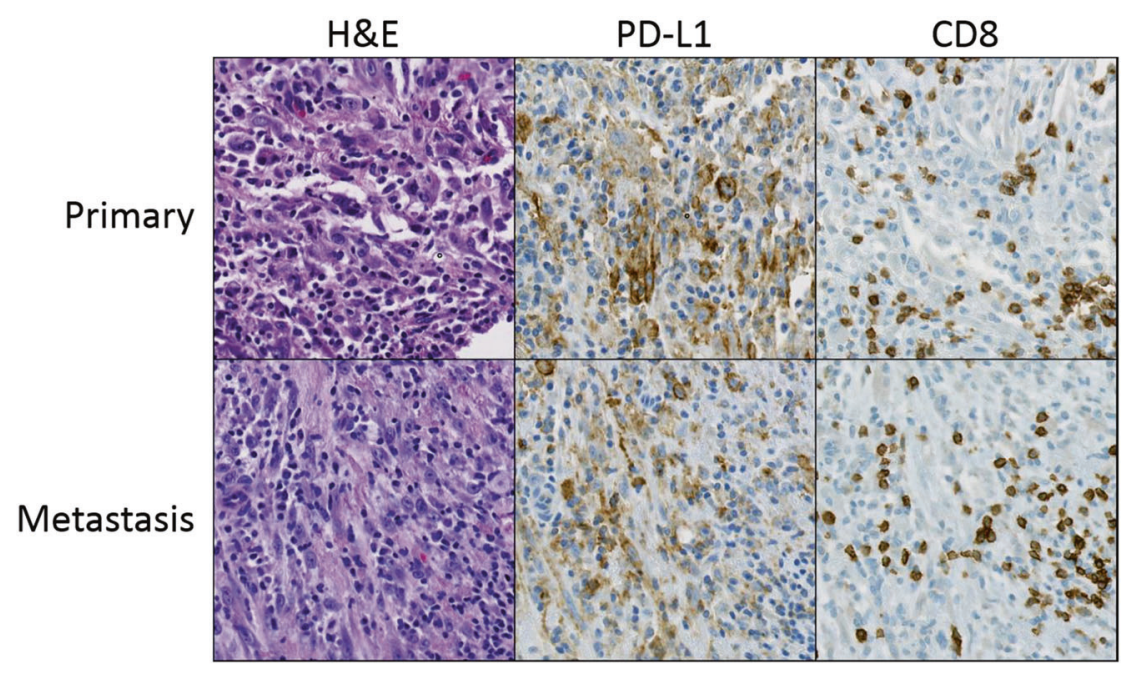

Fig. 2 PD-L1 expression is concordant in paired primary and metastatic inflammatory myofibroblastic tumors. Primary and metastatic specimens from three patients were included in the study and all were concordant for PD-L1 expression. Representative examples, including a primary inflammatory myofibroblastic tumor of the lung (row 1) and chest wall metastasis from the same patient (row 2), stained with H\&E, PD- L1, and CD8 are shown. In both tumors, membranous PD-L1 expression is observed on tumor cells and is associated with $\mathrm{CD} 8^{+} \mathrm{T}$ cell infiltration. Original magnification $\times 200$ 
Table 4 Features of the tumor immune microenvironment and PD-L1 expression in IMTs

\begin{tabular}{|c|c|c|c|c|c|c|}
\hline \multirow[t]{2}{*}{ Characteristic } & \multicolumn{3}{|c|}{ Tumor cell PD-L1 } & \multicolumn{3}{|c|}{ Immune cell PD-L1 } \\
\hline & $\begin{array}{l}\text { Positive } \\
(n=24)\end{array}$ & $\begin{array}{l}\text { Negative }(n= \\
11)\end{array}$ & $p$ value $^{\mathrm{a}}$ & $\begin{array}{l}\text { Positive }(n= \\
28)\end{array}$ & $\begin{array}{l}\text { Negative ( } n= \\
7 \text { ) }\end{array}$ & $p$ value $^{\mathrm{a}}$ \\
\hline \multicolumn{7}{|l|}{ Fusion status ${ }^{\mathrm{b}}$} \\
\hline Positive & $18(75)$ & $10(91)$ & 0.31 & $21(75)$ & $7(100)$ & 0.30 \\
\hline Negative & $6(25)$ & $1(9)$ & & $7(25)$ & $0(0)$ & \\
\hline Lymphoid aggregates & $10(42)$ & $3(27)$ & 0.48 & $12(43)$ & $1(14)$ & 0.22 \\
\hline \multicolumn{7}{|l|}{ Brisk IC infiltrates } \\
\hline Lymphocytes & $18(75)$ & $5(45)$ & 0.13 & $21(75)$ & $2(29)$ & 0.03 \\
\hline Plasma cells & $13(54)$ & $4(36)$ & 0.47 & $15(54)$ & $2(29)$ & 0.40 \\
\hline Eosinophils & $4(17)$ & $0(0)$ & 0.28 & $4(14)$ & $0(0)$ & 0.56 \\
\hline Neutrophils & $1(4)$ & $0(0)$ & 1 & $1(4)$ & $0(0)$ & 1 \\
\hline $\begin{array}{l}\text { CD8 density } \\
\quad\left(\text { cells } / \mathrm{mm}^{2}\right)\end{array}$ & 378 & 134 & $0.085^{\mathrm{c}}$ & 378 & 94 & $0.008^{\mathrm{c}}$ \\
\hline
\end{tabular}

IC immune cells

${ }^{a}$ Fisher's exact test unless otherwise noted

bIncludes ALK-positive and ROS1-rearranged tumors

${ }^{c}$ Wilcoxon rank sum test

Fig. 3 Mixed adaptive and constitutive PD-L1 expression in inflammatory myofibroblastic tumors. H\&E, PD-L1, and CD8 stains of an inflammatory myofibroblastic tumor showing a combination of adaptive and constitutive expression.

Heterogeneous PD-L1 expression can be seen at low power (first column), including diffuse constitutive expression (asterisk) and focal higher intensity adaptive expression (arrowheads). Higher magnification images highlight areas of constitutive expression (second column) and adaptive expression (third column). Original magnification $\times 40$ (first column) and $\times 200$ (second and third columns)

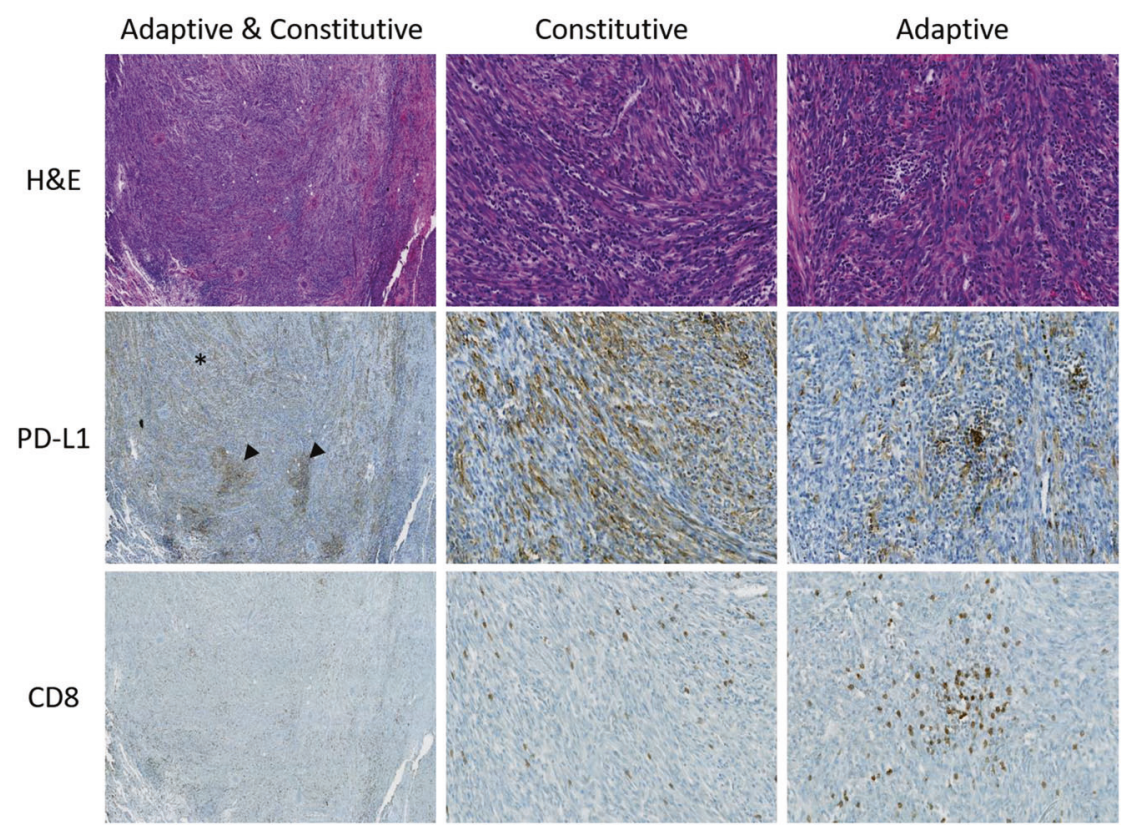

the pediatric population. The majority of specimens studied were primary tumors, although PD-L1 expression in recurrent and metastatic lesions was concordant with the primary ( $n=3$ patients). Finally, assessment of PD-L1 status by histologic subtype and specific genomic alterations was limited by the small sample size. Reproduction of the study findings, ideally in a larger patient cohort, will be important in confirming the significant associations identified in this report. It is also worth emphasizing that the manual PD-L1 immunohistochemistry staining protocol using the SP142 antibody clone in this study is distinct from the FDA-approved automated SP142 PD-L1 immunohistochemistry assay. We and others have previously shown that the SP142 clone itself can demonstrate a similar sensitivity for the detection of PD-L1, depending on assay conditions [28-32]. In summary, we found that PD-L1 expression in inflammatory myofibroblastic tumors is prevalent and associated with tumor infiltrating $\mathrm{CD}^{+} \mathrm{T}$ cells, 
supporting an adaptive immune resistance mechanism of expression. PD-L1 status appears to be independent of ALK status, suggesting that these two features could be considered independent biomarkers. This could be particularly useful clinically in $\mathrm{ALK}(-)$ inflammatory myofibroblastic tumors or those resistant to tyrosine kinase inhibitor therapy. Our findings provide a rationale for further investigation of the utility of checkpoint blockade therapy in treatment refractory inflammatory myofibroblastic tumors.

Acknowledgements We would like to thank Drs. Hao Wang and Ludmila Danilova for statistical consultation, and Jessica Esandrio for administrative assistance. This work was supported by the Melanoma Research Alliance (JMT); Bristol-Myers Squibb (JMT); Sidney Kimmel Cancer Center Core Grant P30 CA006973 (JMT); the National Cancer Institute NIH Grant R01 CA142779 (JMT); NIH Grant T32 CA193145 (TRC). We were also supported by the Bloomberg Kimmel Institute for Cancer Immunotherapy and a Stand Up To Cancer-Cancer Research Institute Cancer Immunology Translational Cancer Research Grant (SU2C-AACR-DT1012). Stand Up to Cancer is a program of the Entertainment Industry Foundation administered by the American Association for Cancer Research.

\section{Compliance with ethical standards}

Conflict of interest JMT receives grant funding from Bristol-Myers Squibb (BMS) and is a consultant/advisory board member for BMS, Merck, and Astra-Zeneca. The remaining authors declare that they have no conflict of interest.

\section{References}

1. Coffin CM, Fletcher JA. Inflammatory myofibroblastic tumor. In: Fletcher CDM, World Health Organization, International Agency for Research on Cancer, editors. WHO classification of tumours of soft tissue and bone. 4th ed. Lyon: IARC Press; 2013.

2. Coffin CM, Hornick JL, Fletcher CD. Inflammatory myofibroblastic tumor: comparison of clinicopathologic, histologic, and immunohistochemical features including ALK expression in atypical and aggressive cases. Am J Surg Pathol. 2007;31: 509-20.

3. Lovly CM, Gupta A, Lipson D, et al. Inflammatory myofibroblastic tumors harbor multiple potentially actionable kinase fusions. Cancer Discov. 2014;4:889-95.

4. Antonescu CR, Suurmeijer AJ, Zhang L, et al. Molecular characterization of inflammatory myofibroblastic tumors with frequent ALK and ROS1 gene fusions and rare novel RET rearrangement. Am J Surg Pathol. 2015;39:957-67.

5. Alassiri AH, Ali RH, Shen Y, et al. ETV6-NTRK3 is expressed in a subset of ALK-negative inflammatory myofibroblastic tumors. Am J Surg Pathol. 2016;40:1051-61.

6. Yamamoto H, Yoshida A, Taguchi K, et al. ALK, ROS1 and NTRK3 gene rearrangements in inflammatory myofibroblastic tumours. Histopathology. 2016;69:72-83.

7. Butrynski JE, D'Adamo DR, Hornick JL, et al. Crizotinib in ALKrearranged inflammatory myofibroblastic tumor. N Engl J Med. 2010;363:1727-33.

8. Taube JM, Klein A, Brahmer JR, et al. Association of PD-1, PD-1 ligands, and other features of the tumor immune microenvironment with response to anti-PD-1 therapy. Clin Cancer Res. 2014;20:5064-74.
9. Sunshine J, Taube JM. PD-1/PD-L1 inhibitors. Curr Opin Pharmacol. 2015;23:32-8.

10. Yanik EL, Kaunitz GJ, Cottrell TR, et al. Association of HIV status with local immune response to anal squamous cell carcinoma: implications for immunotherapy. JAMA Oncol. 2017;3:974-8.

11. Tumeh PC, Harview CL, Yearley JH, et al. PD-1 blockade induces responses by inhibiting adaptive immune resistance. Nature. 2014;515:568-71.

12. Hong S, Chen N, Fang W, et al. Upregulation of PD-L1 by EML4-ALK fusion protein mediates the immune escape in ALK positive NSCLC: implication for optional anti-PD-1/PD-L1 immune therapy for ALK-TKIs sensitive and resistant NSCLC patients. Oncoimmunology. 2016;5:e1094598.

13. Koh J, Jang JY, Keam B, et al. EML4-ALK enhances programmed cell death-ligand 1 expression in pulmonary adenocarcinoma via hypoxia-inducible factor (HIF)-1alpha and STAT3. Oncoimmunology. 2016;5:e1108514.

14. Rangachari D, VanderLaan PA, Shea M, et al. Correlation between classic driver oncogene mutations in EGFR, ALK, or ROS1 and 22C3-PD-L1 expression in lung adenocarcinoma. J Thorac Oncol. 2017;12:878-83.

15. Gainor JF, Shaw AT, Sequist LV, et al. EGFR mutations and ALK rearrangements are associated with low response rates to PD-1 pathway blockade in non-small cell lung cancer: a retrospective analysis. Clin Cancer Res. 2016;22:4585-93.

16. McDermott M. Inflammatory myofibroblastic tumour. Semin Diagn Pathol. 2016;33:358-66.

17. Taube JM, Anders RA, Young GD, et al. Colocalization of inflammatory response with B7-h1 expression in human melanocytic lesions supports an adaptive resistance mechanism of immune escape. Sci Transl Med. 2012;4:127ra37.

18. Habib L, Son JH, Petris C, Kazim M. Spontaneous regression of inflammatory myofibroblastic tumor of the orbit: a case report and review of literature. Orbit. 2017;36:178-82.

19. Lee JC, Li CF, Huang HY, et al. ALK oncoproteins in atypical inflammatory myofibroblastic tumours: novel RRBP1-ALK fusions in epithelioid inflammatory myofibroblastic sarcoma. J Pathol. 2017;241:316-23.

20. Marino-Enriquez A, Wang WL, Roy A, et al. Epithelioid inflammatory myofibroblastic sarcoma: an aggressive intraabdominal variant of inflammatory myofibroblastic tumor with nuclear membrane or perinuclear ALK. Am J Surg Pathol. 2011;35:135-44.

21. D'Angelo SP, Shoushtari AN, Agaram NP, et al. Prevalence of tumor-infiltrating lymphocytes and PD-L1 expression in the soft tissue sarcoma microenvironment. Hum Pathol. 2015;46:357-65.

22. Toulmonde M, Adam J, Bessede A, et al. Integrative assessment of expression and prognostic value of PDL1, IDO, and kynurenine in 371 primary soft tissue sarcomas with genomic complexity. $\mathbf{J}$ Clin Oncol. 2016;34:15_suppl, 11008-11008.

23. Bertucci F, Finetti P, Perrot D, et al. PDL1 expression is a poorprognosis factor in soft-tissue sarcomas. Oncoimmunology. 2017;6:e1278100.

24. Kim C, Kim EK, Jung H, et al. Prognostic implications of PD-L1 expression in patients with soft tissue sarcoma. BMC Cancer. 2016; $16: 434$

25. Kim JR, Moon YJ, Kwon KS, et al. Tumor infiltrating PD1positive lymphocytes and the expression of PD-L1 predict poor prognosis of soft tissue sarcomas. PLoS ONE. 2013;8:e82870.

26. Tawbi HA, Burgess M, Bolejack V, et al. Pembrolizumab in advanced soft-tissue sarcoma and bone sarcoma (SARC028): a multicentre, two-cohort, single-arm, open-label, phase 2 trial. Lancet Oncol. 2017;18:1493-501.

27. Toulmonde M, Penel N, Adam J, et al. Use of PD-1 targeting, macrophage infiltration, and IDO pathway activation in sarcomas: 
a phase 2 clinical trial. JAMA Oncol. 2017. https://doi.org/10. 1001/jamaoncol.2017.1617.

28. Ratcliffe MJ, Sharpe A, Midha A, et al. Agreement between programmed cell death ligand-1 diagnostic assays across multiple protein expression cutoffs in non-small cell lung cancer. Clin Cancer Res. 2017;23:3585-91.

29. Hirsch FR, McElhinny A, Stanforth D, et al. PD-L1 immunohistochemistry assays for lung cancer: results from phase 1 of the blueprint PD-L1 IHC assay comparison project. J Thorac Oncol. 2017;12:208-22.
30. Rimm DL, Han G, Taube JM, et al. A prospective, multi-institutional, pathologist-based assessment of 4 immunohistochemistry assays for PD-L1 expression in non-small cell lung cancer. JAMA Oncol. 2017;3:1051-8.

31. Gaule P, Smithy JW, Toki M, et al. A quantitative comparison of antibodies to programmed cell death 1 ligand 1. JAMA Oncol. 2017;3:256-9.

32. Sunshine JC, Nguyen PL, Kaunitz GJ, et al. PD-L1 expression in melanoma: a quantitative immunohistochemical antibody comparison. Clin Cancer Res. 2017;23:4938-44. 